\title{
The Evolving Family Medicine Team
}

\author{
Yalda Jabbarpour, MD, Anuradha Jetty, MPH, Mingliang Dai, PhD, \\ Michael Magill, MD, and Andrew Bazemore, MD, MPH
}

A decade of practice transformation, consolidation, and payment experimentation have highlighted the need for team-based primary care, but little is known about how team composition is changing over time. Surveys of Family Physicians (FPs) from 2014-18 reveal they continue to work alongside inter-professional team members and suggest slow but steady growth in the proportion of FPs working with nurses, behaviorists, clinical pharmacists, and social workers. ( J Am Board Fam Med 2020;33:499-501.)

Keywords: Family Physicians, Health Policy, Patient Care Team, Primary Health Care, Surveys and Questionnaires

Team-based care is the cornerstone of practice transformation. Evidence suggests that a teambased structure is essential if our primary care workforce is to meet the chronic and preventive care needs of our population. ${ }^{1}$ Team compositions have been proposed for different adult patient populations based on "exemplary" primary care practices, but it is unclear what teams actually exist across the universe of family practices. ${ }^{2}$ Previous work has shown that a majority of family physicians report working with nurse practitioners (NPs). Fewer work with nonbilling team members such as social workers. ${ }^{3}$ Yet, as the nonphysician workforce grows and alternative payment models that support the addition of nonbilling providers expands, the landscape of teams in family medicine is likely to change. Given the importance of team-based care, and the emergence of different models for team compositions, it is important to understand how family medicine teams are evolving over time.

This article was externally peer reviewed.

Submitted 28 October 2019; revised 19 February 2020; accepted 24 February 2020.

From the Robert Graham Center for Policy Studies in Primary Care, Washington, DC (TJ, AJ); The American Board of Family Medicine, Lexington, KY (MD, MM, AB); University of Utah School of Medicine, Salt Lake City (MM); Center for Professionalism and Value in Healthcare, Washington, DC (AB).

Funding: None.

Disclosures: None.

Conflicts of interest: None.

Corresponding author: Yalda Jabbarpour, MD, the Robert Graham Center, 1133 Connecticut Ave NW, Washington, DC 20036 (E-mail: yjabbarpour@aafp.org).
We used data from the American Board of Family Medicine examination application questionnaire for the years 2014 to 2018, a repeated annual cross-sectional census. With a $100 \%$ response rate of the approximately $10 \%$ of American Board of Family Medicine[en]certified physicians who take the examination each year, the survey provides a representative sample of board-certified family physicians' practices. In each year family physicians who answered that they were providing continuity outpatient care were asked: "Which of the following types of health professionals work (collaboratively) with you at your principal practice site?" and were given a list of allied professionals from which to choose. The word 'collaboratively' was added to this question beginning in 2017. If physicians applied for the examination multiple times, we used their most recent response. We limited the analysis to family physicians (FPs) in direct patient care. We calculated the annual prevalence for each type of team member and calculated the $c^{2}$ to test the significance of the trend.

Across annual samples of 8000 to 11,000 family physicians, roughly half reported working with a $\mathrm{NP}$, registered nurse (RN) or, in more recent years, a licensed practical nurse (LPN), with LPN's seeing the largest increase over the time period studied. Nearly a quarter of family physicians worked with clinical pharmacists, behaviorists, and social workers in 2018, with all 3 seeing increases over the preceding 4 years. While there has been a growth in family physicians working with NPs and PAs over the time period, the number does not continually 
Table 1. Percent Family Physicians Working Alongside Other Healthcare Providers by Year

\begin{tabular}{|c|c|c|c|c|c|}
\hline Year & $\begin{array}{c}2014 \\
(\mathrm{n}=10,836)\end{array}$ & $\begin{array}{c}2015 \\
(\mathrm{n}=9,198)\end{array}$ & $\begin{array}{c}2016 \\
(\mathrm{n}=9,780)\end{array}$ & $\begin{array}{c}2017 \\
(\mathrm{n}=8,161)\end{array}$ & $\begin{array}{c}2018 \\
(\mathrm{n}=8,026)\end{array}$ \\
\hline \multicolumn{6}{|l|}{ Provider } \\
\hline Nurse Practitioner* & 54.0 & 55.9 & 59.9 & 53.7 & 55.9 \\
\hline Registered Nurse* & 47.0 & 48.7 & 49.8 & 53.5 & 53.8 \\
\hline Physician Assistant* & 41.3 & 42.8 & 44.3 & 41.6 & 42.5 \\
\hline Licensed Practical Nurse* & 34.5 & 35.1 & 37.1 & 49.7 & 49.3 \\
\hline Clinical pharmacist* & 21.7 & 22.9 & 24.8 & 24.9 & 25.8 \\
\hline Behavior Specialist* & 21.2 & 22.7 & 24.2 & 24.5 & 26.3 \\
\hline Social Worker* & 20.9 & 22.0 & 24.6 & 24.0 & 26.3 \\
\hline PT/OT & 14.8 & 16.4 & 17.5 & 14.5 & 14.4 \\
\hline Psychiatrist & 12.1 & 12.5 & 14.2 & 13.1 & 13.1 \\
\hline Midwife & 4.6 & 4.0 & 4.3 & 4.6 & 5.0 \\
\hline
\end{tabular}

Source: 2014, 2015, 2016, 2017, and 2018 American Board of Family Medicine Recertification Examination Application Surveys.

PT, physical therapist; OT, occupational therapist.

*Significant to the $P<.001$.

increase from year to year. Slight language changes in the survey item (noted above) could have impacted responses after 2016 (Table 1).

These findings suggest that a majority of family physicians worked with nonphysician providers over the 5 years studied. A few limitations must be considered when interperting these results. First, our questionnaire did not ask about presence of medical assistants (MAs) in the team until 2017, so we could not include this data. Advanced-role MAs are important members of primary care teams ${ }^{4}$ and future research should assess MA numbers and roles. In addition, although we added the term "collaboratively" in 2017, the survey does not clarify whether FPs are actually working within interprofessional teams versus practicing adjacent to, but not with, others. ${ }^{5}$ Finally, we cannot assess nuanced differences between teams such as combinations of team members or proportion of each type of health professional on the team. Despite these limitations, we found some interesting trends in the data over the time period studied. Specifically, we found steady, year-to-year increases in the percentage of family physicians working with certain types of providers (RN, LPN, Social Worker), but not others (NP, PA, PT/OT). The addition of the word "collaboratively" to the survey in 2017 may have caused the drop in percentage we see between 2016 to 2017 for PAs and NPs. Alternatively, the trends we see could be more representative of changes in the health professional workforce overall. In particular, the percentage of family physicians who reported working with LPN's grew more than any other group in this time period. A general increase in the production of LPNs over the past decade combined with a shift in LPNs from the inpatient to the outpatient setting may explain these results. ${ }^{6,7}$ Overall, nonbilling providers (RNs, LPNs, Social Workers) on the family medicine team increased more substantially than billing providers (NPs, PAs) over the time period studied. Perhaps a growth of alternative payment models over the study period supported the addition of these nonbilling providers, or, the increase in nonbilling providers may simply suggest that their skills are the most needed for advanced primary care models. As practices continue to transform and new payment models emerge, further work is necessary to determine the optimal composition of teams in family medicine.

To see this article online, please go to: http://jabfm.org/content/ 33/4/499.full.

\section{References}

1. Ghorob A, Bodenheimer T. Sharing the Care to Improve Access to Primary Care. N Engl J Med 2012;366:1955-7.

2. Meyers D, LeRoy L, Bailit M, Schaefer J, Wagner E, Zhan C. Workforce configurations to provide highquality, comprehensive primary care: a mixed-method exploration of staffing for four types of primary care practices. J Gen Intern Med 2018;33:1774-9.

3. Bazemore A, Wingrove P, Peterson L, Petterson S. The diversity of providers on the family medicine team. J Am Board Fam Med 2016;29:8-9.

4. Sinsky CA, Bodenheimer T. Powering-up primary care teams: advanced team care with in-room support. Ann Fam Med 2019;17:367-71. 
5. Reeves S, Xyrichis A, Zwarenstein M. Teamwork, collaboration, coordination, and networking: Why we need to distinguish between different types of interprofessional practice. J Interprof Care 2018;32:1-3.

6. A Vision for Recognition of the Role of Licensed Practical/Vocational Nurses in Advancing the Nation's Health. 2014. http://www.nln.org/docs/ default-source/about/nln-vision-series-\%28positionstatements\%29/nlnvision_7.pdf.

7. The US Nursing Workforce: Trends in Supply and Education. Health Resources and Service Administration, Bureau of Health Professions (HRSA). http:// bhpr.hrsa.gov/healthworkforce/supplydemand/nursing/ nursingworkforce/. 